\title{
Infectious Tenosynovitis in a Patient with Dermatopolymyositis and Vasculitis
}

CLARISSA CANELLA, MD, Clínica de Diagnóstico por Imagem; Serviço de Radiologia e Diagnóstico por Imagem da Universidade Federal do Rio de Janeiro - UFRJ; MARCELO PACHECO, MD, Serviço de Reumatologia do Hospital dos Servidores do Estado; FLAVIA COSTA, MD, Clínica de Diagnóstico por Imagem; Serviço de Radiologia e Diagnóstico por Imagem da UFRJ; EDSON MARCHIORI, PhD, Serviço de Radiologia e Diagnóstico por Imagem da UFRJ, Rio de Janeiro, Brazil. Address correspondence to Dr. C. Canella, Clinica de Diagnóstico por Imagem, Avenida das Americas 4666, sala 325, Rio de Janeiro, RJ 22630010, Brazil. E-mail: clacanella@yahoo.com.br. J Rheumatol 2013;40:949; doi:10.3899/jrheum.121434

Flexor tendon sheath infection calls for appropriate antimicrobial and surgical therapy to overcome complications such as deep abscesses, septic arthritis, and osteomyelitis.

A 33-year-old woman with dermatopolymyositis and vasculitis for 1 year was diagnosed by typical rash (heliotrope rash, Gottron's sign), symmetric proximal muscle weakness, elevated serum skeletal muscle enzymes, electromyographic abnormalities, and interstitial lung disease. She started intravenous (IV) methylprednisolone 1 g/day for 3 days, followed by monthly IV cyclophosphamide and oral prednisone $1 \mathrm{mg} / \mathrm{kg} /$ day. After 2 months, the right fourth finger exhibited painful erythematous bullous lesions (Figure 1a, arrows). She did not present any systemic symptoms. Laboratory examinations showed white blood cell count 4900 and C-reactive protein $0.07 \mathrm{mg} / \mathrm{dl}$. Sagittal (Figure 1b) and axial (Figure 1c) T1-weighted, gadolinium-enhanced magnetic resonance imaging (MRI) scans with fat saturation sequences showed extensive fluid collection with peripheral contrast enhancement of the fourth flexor tendon synovial sheath, indicating abscess (Figure 1b, 1c, arrows). Following fluid drainage 3 days after MRI, infectious tenosynovitis was confirmed and multisensitive Staphylococcus aureus was isolated. After 4 months of treatment, bullous lesions were completely resolved, without any sequela.

Tenosynovitis has been described in adult-onset dermatopolymyositis involving the hand, especially in patients with skin ulcers and calcinosis, and can cause recurrent extensor tendon rupture ${ }^{1}$. Causes of flexor tendon sheath infection (most commonly S. aureus, Streptococcus species) must be diagnosed, and appropriate medical or surgical treatment undertaken, to avoid poor clinical outcomes $^{1,2,3}$. Treatment involves antimicrobial therapy, immobilization, edema control, and appropriate surgical therapy to prevent complications such as deep abscesses, septic arthritis, and osteomyelitis ${ }^{2,3}$.

\section{REFERENCES}

1. Nakamura S, Nakagawa J. Recurrent extensor tendon rupture in adult-onset dermatomyositis: a case report. Clin Rheumatol 2005;24:409-10.

2. Draeger RW, Bynum DK Jr. Flexor tendon sheath infections of the hand. J Am Acad Orthop Surg 2012;20:373-82.

3. Turecki MB, Taljanovic MS, Stubbs AY, Graham AR, Holden DA, Hunter TB, et al. Imaging of musculoskeletal soft tissue infections. Skeletal Radiol 2010;39:957-71.

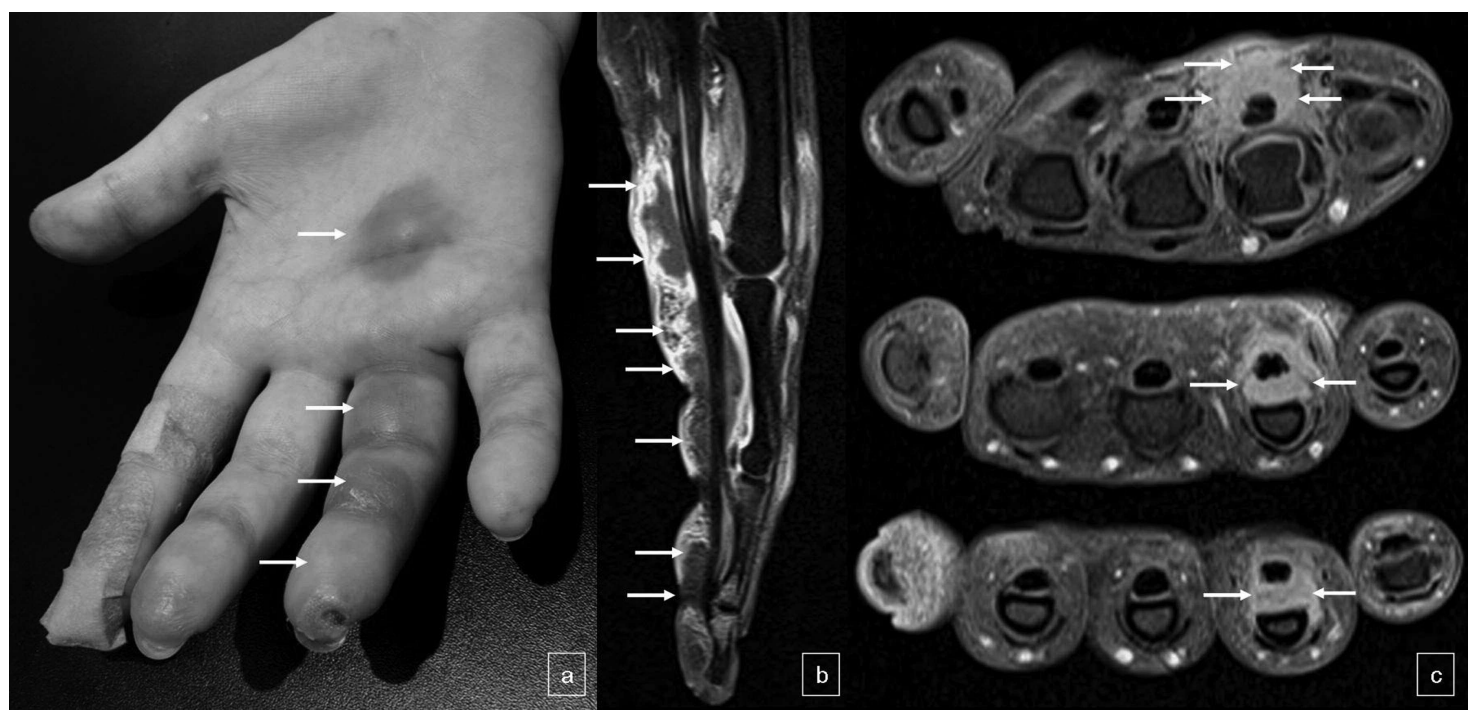

Figure 1. A. The right fourth finger exhibited erythematous bullous lesions (arrows). B and C. Magnetic resonance imaging scans showed extensive fluid collection with peripheral contrast enhancement of the fourth flexor tendon synovial sheath, indicating abscess (arrows). 